\title{
Blocking interleukin-6 signaling inhibits cell viability/proliferation, glycolysis, and colony forming activity of human medulloblastoma cells
}

\author{
XIANG CHEN $^{1}$, JIA WEI ${ }^{1}$, CHENGLONG LI $^{2}$, CHRISTOPHER R. PIERSON $^{3}$, \\ JONATHAN L. FINLAY ${ }^{4}$ and JIAYUH LIN ${ }^{1}$
}

\begin{abstract}
${ }^{1}$ Department of Biochemistry and Molecular Biology, School of Medicine, University of Maryland, Baltimore, MD 21201;
${ }^{2}$ College of Pharmacy, University of Florida, Gainesville, FL 32610; ${ }^{3}$ Department of Pathology and Laboratory Medicine,

Nationwide Children's Hospital, The Department of Pathology and Division of Anatomy, College of Medicine,

The Ohio State University; ${ }^{4}$ Hematology and Oncology, The Research Institute at Nationwide Children's Hospital,

Department of Pediatrics, College of Medicine, The Ohio State University, Columbus, OH 43205, USA
\end{abstract}

Received April 13,2017; Accepted August 23, 2017

DOI: $10.3892 /$ ijo.2017.4211

\begin{abstract}
Elevated levels of the pro-inflammatory cytokine interleukin-6 (IL-6) have tumor-promoting activity and are associated with poor survival outcomes in many cancers. Additionally, the IL-6/GP130/STAT3 axis has been widely studied due to its pivotal role in tumor development and maintenance in a number of tissue types, including the cerebellum. However, the connection between IL-6 signaling and medulloblastoma progression is largely unexplored. In the present study, we observed that IL-6 induced medulloblastoma cell viability, cell proliferation and glycolysis. Furthermore, it also upregulated the expression of phosphorylated STAT3, indicating that the IL-6/GP130/STAT3 pathway plays a central role in medulloblastoma. The FDA-approved drug bazedoxifene, a blocker of the formation of the hexameric IL-6/IL-6R/GP130 complex, was re-purposed in this study to inhibit the IL-6/GP130/STAT3 signaling pathway. Bazedoxifene not only inhibited IL-6 mediated cell viability and cell proliferation, and increased phosphorylated STAT3 expression, but it also decreased cell glycolysis, demonstrating a certain level of therapeutic efficacy in vitro. Collectively, our findings offer new insight into the molecular mechanism underlying the biological aggressiveness of medulloblastoma, the roles of IL-6 in these processes and a possible efficacious adjuvant therapy for medulloblastoma.
\end{abstract}

Correspondence to: Professor Jiayuh Lin, Department of Biochemistry and Molecular Biology, University of Maryland Marlene and Stewart Greenebaum Comprehensive Cancer Center, University of Maryland School of Medicine, 108 N. Greene Street, Baltimore, MD 21201, USA

E-mail: jlin@som.umaryland.edu

Key words: IL-6/GP130/STAT3, medulloblastoma, bazedoxifene, SC144, cell proliferation

\section{Introduction}

Medulloblastoma is the most common malignant pediatric brain tumor, accounting for $\sim 63.7 \%$ of all embryonal brain tumors in children and adolescents $(1,2)$. The current consensus recognizes four genetic (molecular) subgroups of medulloblastoma, including Wingless (Wnt), Sonic hedgehog (SHH), and the numerically designated 'group 3' and 'group 4' $(3,4)$. Therapy regimens using a combination of surgery, craniospinal radiotherapy, and chemotherapy with vincristine, cisplatin and cyclophosphamide result in an overall survival rate of 70-80\%; however, survivors are at increased risk to develop long-term sequelae such as neurocognitive impairment, endocrinopathies and neurologic deficits (5-7). Therefore, medulloblastoma still represents a major clinical challenge in pediatric oncology, and demands the development of targeted approaches with less toxic side effects while preserving therapeutic effectiveness.

Interleukin-6 (IL-6) belongs to a large family of multifunctional cytokines. Besides its functions in inflammation and immune regulation, it plays a crucial role in the development of various types of cancer $(8,9)$, and regulates most of the hallmarks of cancer, including promotion of survival $(10,11)$, proliferation (12,13), angiogenesis (14), and cancer cell invasion and metastasis $(15,16)$; it is also a pivotal contributor to cancer cell metabolism $(17,18)$. Emerging evidence suggests that high serum levels of IL-6 are observed in multiple cancer types, implying a strong association between IL-6 and cancer (19-21). IL-6 binds to and exerts its function via the IL-6 receptor (IL-6R), the resultant IL-6/IL-6R complex then recruits GP (glycoprotein) 130 leading to GP130 homo-dimerization to form a hexameric structure consisting of two molecules each of IL-6, IL-6R and GP130 (18,22). IL-6/IL-6R/GP130 complex formation results in GP130 tyrosine phosphorylation which can enhance tumor cell survival and proliferation by triggering several cell signaling events, including the Ras/Raf/ MEK/MAPK (mitogen-activated protein kinase), PI3K/AKT (phosphatidylinositol 3-kinase/a serine/threonine kinase) and JAK/STAT (Janus kinase/signal transducer and activator 
of transcription) pathways via GP130 tyrosine phosphorylation $(13,23,24)$. Mounting evidence indicates that activation of IL-6/GP130/STAT3 signaling is an important event in a number of cancer types and it promotes tumorigenesis by regulating multiple survival signaling pathways in cancer cells (25-27).

In light of the above, inhibition of the IL-6/GP130/STAT3 axis was considered to have therapeutic potential in cancer and IL-6 and IL-6R blocking antibodies (e.g., tocilizumab), JAK inhibitors, and STAT3 inhibitors have been developed and tested (28-32). A number of IL-6 ligand binding antibodies and IL-6R blocking antibodies have been developed and are currently in clinical trials. Among these, a small molecule JAK inhibitor, tofacitinib, and a humanized monoclonal antibody targeting human IL-6R, tocilizumab, have been approved by the FDA (33). However, tofacitinib has the capacity to block the activity of most cytokines, and tocilizumab could cause a dramatic increase in systemic IL-6 levels and an increased risk of infections (34).

Currently, new uses of classical small molecules are playing a critical role in drug discovery. In our previous studies, the FDA-approved drug bazedoxifene was re-purposed as a novel small molecular inhibitor of trimetric IL-6/IL-6R/GP130 complex, suppressing tumor growth and inducing apoptosis in human cancer cells and a xenograft model $(35,36)$. Herein, we investigated the efficacy of bazedoxifene on the IL-6/IL-6R/ GP130 pathway and its effects on medulloblastoma cells. Targeting the IL-6/GP130/STAT3 axis using bazedoxifene inhibited IL-6 enhanced cell viability, proliferation, glycolysis and reduced clonogenicity in colony formation. These results suggest that bazedoxifene is a potent inhibitor against the IL-6/GP130/STAT3 signaling pathway and may be of use clinically.

\section{Materials and methods}

Cell culture and reagents. The medulloblastoma cell lines (DAOY and UW288) were provided by Dr Corey Raffel (The Research Institute at Nationwide Children's Hospital). Cells were maintained in 1X Dulbecco's modified Eagle's medium (DMEM) with $4.5 \mathrm{~g} / \mathrm{l}$, L-glutamine and sodium pyruvate (Mediatech, \#10013 CV) supplemented with $10 \%$ fetal bovine serum (FBS) (Atlanta Biologicals, \#S11150), and $1 \%$ penicillin/streptomycin (P/S) (Sigma, \#P0781) in incubators set at $37^{\circ} \mathrm{C}$ and aired with $5 \% \mathrm{CO}_{2}$.

The reagents in the study were as follows: recombinant human IL-6 (Cell Signaling Technology, \#8904SF), bazedoxifene (Sigma, \#PZ0018), 3-(4, 5-dimethylthiazol-2-yl)-2, 5-diphenyltetrazolium bromide (MTT) (Sigma, \#M5655), N, N-dimethylformamide (DMF) (Fisher, \#D119-4), dimethyl sulfoxide (DMSO) (Sigma, \#D2650), and crystal violet (Sigma, \#C6158). The stock solution of bazedoxifene was prepared by transferring $10 \mathrm{mg}$ to the DMSO at a concentration of $20 \mathrm{mM}$. IL-6 powder was dissolved in sterile PBS to make a $100 \mathrm{ng} / \mu 1$ stock solution. Aliquots of the stock solutions were stored at $-20^{\circ} \mathrm{C}$. All other chemicals used were analytical grade without purification.

MTT assay. Cells were seeded in 96-well plates in triplicate at the density of 3,000 cells per well and allowed to adhere overnight. Cells were treated with IL-6 or inhibitors with different concentrations in the presence of $0 \% \mathrm{FBS}$ for $48 \mathrm{~h}$ at $37^{\circ} \mathrm{C}$. 3-(4, 5-dimethylthiazol-2-yl)-2, 5-diphenyltetrazolium bromide (MTT) dye $(20 \mu 1,5 \%$, w/v) was added to each well. Subsequently, the plates were incubated at $37^{\circ} \mathrm{C}$ for $4 \mathrm{~h}$. Thereafter, DMF solubilization solution $(150 \mu \mathrm{l})$ was then added to each sample with gentle shaking overnight. Absorbance was measured at $595 \mathrm{~nm}$. Combination index (CI) was calculated by CompuSyn software. Bazedoxifene (10 and $15 \mu \mathrm{M})$ is combined either with the STAT3 inhibitor, BP-1-102 (5, 10 and $15 \mu \mathrm{M})$, or the GP130 inhibitor, $\operatorname{SC144}(5,10$ and $15 \mu \mathrm{M})$, in UW288 and DAOY cells.

Cell proliferation assay. Cell proliferation was measured using Bromodeoxyuridine (BrdU) Cell Proliferation assay kit (Cell Signaling Technology, \#6813S). Eight thousand cells per well were seeded in 96-well plates in triplicate and allowed to adhere overnight. Cells were treated with serial dilutions of IL-6 or drugs in serum-free medium and incubated at $37^{\circ} \mathrm{C}$ for $24 \mathrm{~h}$. The following day the medium was changed to $1 \mathrm{X}$ BrdU solution prepared in 0\% FBS medium and incubated for $1 \mathrm{~h}$ at $37^{\circ} \mathrm{C}$ to induce cell proliferation and BrdU incorporation during $\mathrm{S}$-phase. The rest of the procedure was performed according to the manufacturer's instructions. The BrdU incorporation was measured at $450 \mathrm{~nm}$ using a microplate reader.

Western blot assay. Medulloblastoma cell lines (DAOY and UW288) were washed with cold PBS and harvested with a rubber scraper after treatment. Cell pellets were kept on ice and lysed for $20 \mathrm{~min}$ in cell lysis buffer (Cell Signaling Technology, \#9803) containing protease inhibitor cocktail and phosphatase inhibitors. The lysates were cleared by centrifugation, and the supernatant fractions were collected. Cell lysates were then separated by $10 \%$ SDS-PAGE and subjected to western blot analysis with 1:1,000 dilution of primary antibodies and 1:10,000 horseradish peroxidase-conjugated secondary antibodies. Antibodies against the following were used for western blotting: phosphorylated STAT3 (Y705), STAT3, phosphorylated p44/42 MAPK (ERK1/2) (Thr202/Tyr204), ERK, phosphorylated AKT (Ser473), AKT, phospho-S6 ribosomal protein (Ser235/236), cyclin D1, and GAPDH. All primary and secondary antibodies were purchased from Cell Signaling Technology. GAPDH served as the loading control in all experiments. Membranes were analyzed using SuperSignal ${ }^{\mathrm{TM}}$ West Femto Maximum Sensitivity Substrate (Thermo, \#34096).

Glycolysis. Extracellular L-lactate was detected in cultured cells using Glycolysis Cell-Based assay kit (Cayman, \#600450). Assays were performed following the manufacturer's instructions. Cells $\left(1 \times 10^{4}\right)$ per well were seeded in 96 -well plates in triplicate and allowed to adhere overnight. Cells were treated with IL-6 or with the other agents under study in the presence of $0 \%$ FBS. After 48-h incubation, $10 \mu \mathrm{l}$ of supernatant from each well was transferred to the corresponding wells on the new plates. Reaction solution (100 $\mu \mathrm{l})$ containing assay buffer, glycolysis assay substrate, glycolysis assay cofactor, and glycolysis assay enzyme mixture was added to each well with gentle shaking for $30 \mathrm{~min}$ at room temperature, after which the absorbance was read at $490 \mathrm{~nm}$. 
A
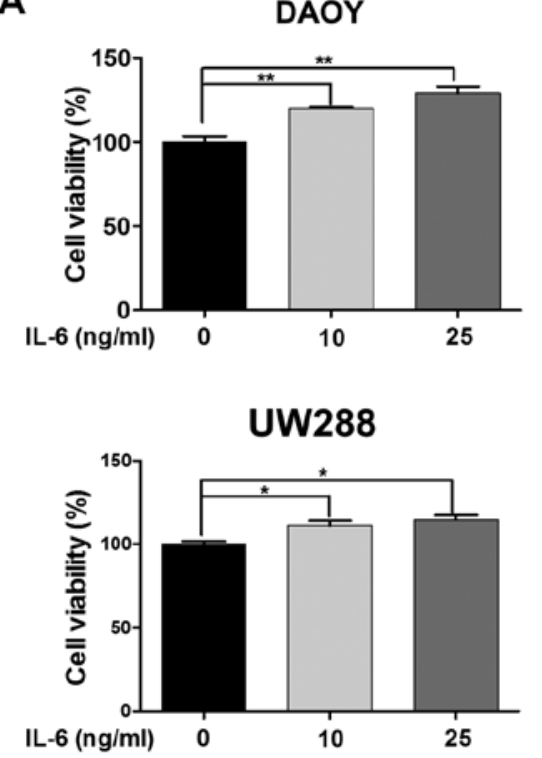

B

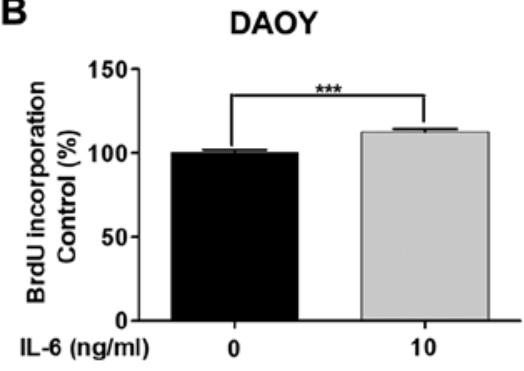

UW288

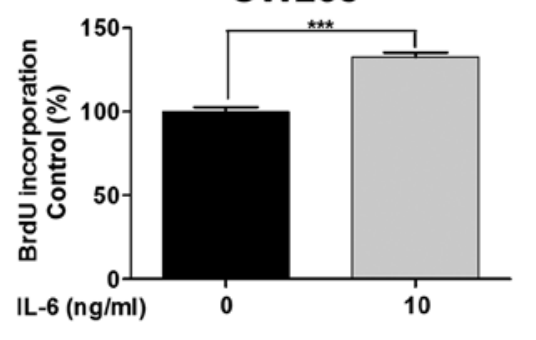

C

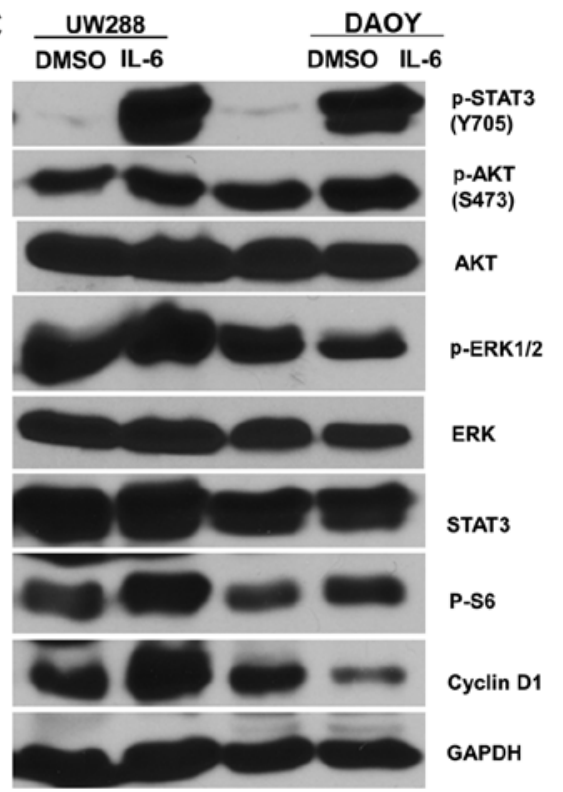

Figure 1. IL-6 stimulates cell viability and cell proliferation as well as upregulated constitutive phosphorylation of STAT3 in medulloblastoma cells. (A) DAOY and UW288 cells were exposed with recombinant human IL-6 (0, 10 and $25 \mathrm{ng} / \mathrm{ml})$ for $48 \mathrm{~h}$. After that, cell viability was measured using MTT assays in triplicate. (B) DAOY and UW288 cells were treated with recombinant human IL-6 $(0,10$ and $25 \mathrm{ng} / \mathrm{ml})$ for $24 \mathrm{~h}$. Cell proliferation was detected by BrdU assay. (C) Western blot analysis of p-STAT3 (Y705), STAT3, p-AKT (S473), AKT, p-ERK (T202/Y204), ERK, p-S6 and cyclin D1 were conducted after addition of IL-6 (10 ng/ml) for $30 \mathrm{~min}$ in DAOY and UW288 cells. ${ }^{*} \mathrm{P}<0.05,{ }^{* *} \mathrm{P}<0.01,{ }^{* * *} \mathrm{P}<0.001$.

Colony forming cell assay. Clonogenic capacity was evaluated according to the protocol of Franken et al (37). Cells were treated with bazedoxifene $(10,15$ and $20 \mu \mathrm{M})$ and SC144 $(10,15$ and $20 \mu \mathrm{M}$ ) for $16 \mathrm{~h}$. After treatment, cells were harvested and reseeded on $6-\mathrm{cm}$ plates with a drug-free medium for an additional incubation of 2 weeks. Colonies were fixed with methanol and stained with crystal violet dye $(0.1 \% \mathrm{w} / \mathrm{v})$.

Statistical analysis. All results are shown as the means \pm standard error of the mean (SEM). The difference between two groups was analyzed using the Student's t-test. All statistical analyses were conducted on the GraphPad Prism 5.0 software $(\mathrm{P}<0.05, \mathrm{P}<0.01, \mathrm{P}<0.001)$.

\section{Results}

IL-6 promotes cell viability in medulloblastoma cells. It is well established that elevated serum levels of IL-6 are associated with aggressiveness of many human cancers, including pancreatic, prostate and breast cancer (19-21). To evaluate the association of IL-6 and medulloblastoma, we tested the influence of exogenous IL-6 on the viability of medulloblastoma cells as determined using the MTT assay. Two medulloblastoma cell lines DAOY and UW288 were treated with different doses of recombinant human IL-6 $(0-25 \mathrm{ng} / \mathrm{ml})$, and incubated for $48 \mathrm{~h}$. As a result, stimulation of the cell viability was significantly enhanced in DAOY and UW288 cells, which was significant at $10 \mathrm{ng} / \mathrm{ml}$ of IL-6 (Fig. 1A).

IL-6 stimulates cell proliferation and upregulates the expression of phosphorylated STAT3 in medulloblastoma cells. To further evaluate the association of IL- 6 and medulloblastoma, we tested the impact of exogenous IL- 6 on the proliferation of medulloblastoma cells using a BrdU incorporation assay, which determines changes in cell proliferation rates over time by measuring cell DNA incorporation. DAOY and UW288 cells were exposed to different concentrations of IL-6 $(0-25 \mathrm{ng} / \mathrm{ml})$ for $24 \mathrm{~h}$. As shown in Fig. 1B, increased incorporation of BrdU into DNA was observed in these two cell lines in response to IL-6, which was significant at $10 \mathrm{ng} / \mathrm{ml} \mathrm{IL-6,} \mathrm{indicating} \mathrm{that}$ IL-6 induced cell proliferation of DAOY and UW288 cells.

To further assess the effect of IL-6 on STAT3 phosphorylation, the principal signaling molecule activated by IL-6, we treated DAOY and UW288 cells with $10 \mathrm{ng} / \mathrm{ml} \mathrm{IL-6}$ and observed an early (30 min) increase in the expression of phosphorylated STAT3 at tyrosine residue 705 (Y705). Western blot analysis revealed that IL-6 induced the expression of phosphorylated STAT3 at the protein level, but had no noticeable effect on the phosphorylation of other protein kinase pathways, such as Ras/Raf/MEK/MAPK, PI3K/ AKT pathways, suggesting that IL-6, selectively triggers the JAK/STAT3 pathway in medulloblastoma cells (Fig. 1C).

Bazedoxifene impairs IL-6 mediated cell viability in medulloblastoma cells. The FDA-approved drug bazedoxifene is well known as a selective estrogen receptor modulator (SERM); it also exhibits antitumor activity $(35,36)$. We evaluated whether bazedoxifene could suppress cell viability mediated by IL-6 in DAOY and UW288 cells. Cells were pre-treated with different concentrations of bazedoxifene $(5,10$ and $20 \mu \mathrm{M})$ for $4 \mathrm{~h}$ followed by stimulation of exogenous IL-6 (10 ng/ml). After $48 \mathrm{~h}$ of treatment, IL-6 mediated cell viability was suppressed in a dose-responsive manner (Fig. 2A). In addition, the $\mathrm{IC}_{50}$ values of bazedoxifene in UW288 and DAOY cell lines were $5.65 \pm 0.97$ and $12.05 \pm 0.20 \mu \mathrm{M}$, respectively. To further investigate the potential of inhibiting IL- 6 signaling in the treatment of medulloblastoma, we tested the effects of the reported GP130 inhibitor, SC144 and the STAT3 inhibitor, BP-1-102 on 

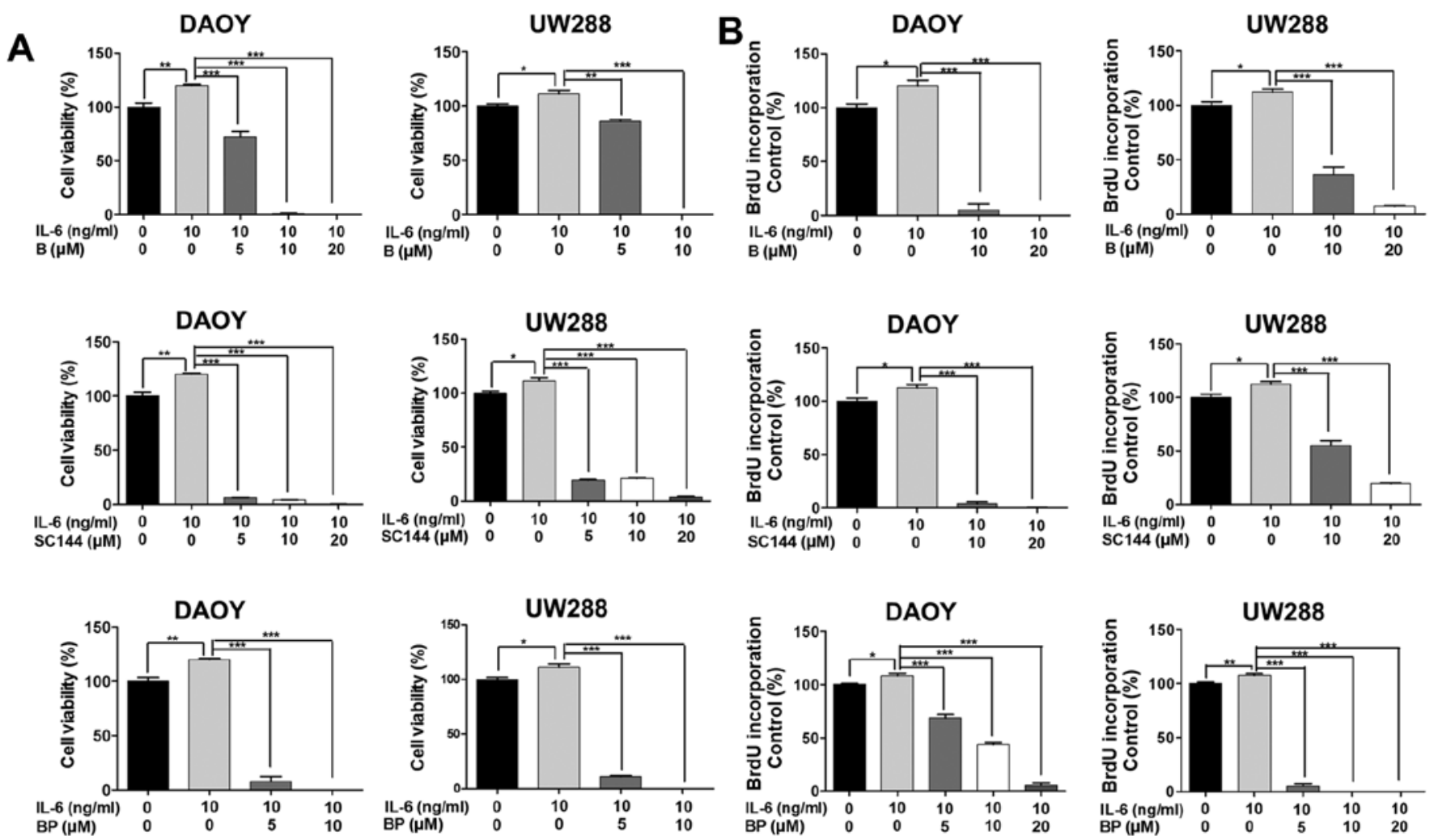

Figure 2. Bazedoxifene and other inhibitors blocked IL-6 induced cell viability and cell proliferation. (A) DAOY and UW288 cells were pretreated with bazedoxifene $(5,10$ and $20 \mu \mathrm{M})$, SC144 $(5,10$ and $20 \mu \mathrm{M})$, or BP-1-102 (5, 10 and $20 \mu \mathrm{M})$ for $4 \mathrm{~h}$, followed by addition of recombinant human IL-6 (10 ng/ml). After 48-h treatment, cell viability was determined using MTT assay. (B) DAOY and UW288 cells were pretreated with bazedoxifene $(5,10$ and $20 \mu \mathrm{M}), \mathrm{SC} 144$ $(5,10$ and $20 \mu \mathrm{M})$, or BP-1-102 $(5,10$ and $20 \mu \mathrm{M})$ for $4 \mathrm{~h}$, followed by addition of recombinant human IL-6 $(10 \mathrm{ng} / \mathrm{ml})$. Cell proliferation was measured using BrdU assay after treatment for $24 \mathrm{~h}$. B, bazedoxifene; BP, BP-1-102. ${ }^{*} \mathrm{P}<0.05,{ }^{* *} \mathrm{P}<0.01,{ }^{* * * *} \mathrm{P}<0.001$.

these two cell lines. SC144 and BP-1-102 effectively inhibited IL-6-induced cell viability (Fig. 2A). To evaluate any possible synergism between bazedoxifene, BP-1-102 and SC144, we calculated CI values of bazedoxifene and BP-1-102, as well as bazedoxifene and SC144 in both UW288 and DAOY cells. The results indicated no synergistic effects.

Bazedoxifene inhibits IL-6 induced cell proliferation in medulloblastoma cells. To assess whether bazedoxifene could inhibit cell proliferation induced by IL-6 in medulloblastoma cells, we pretreated DAOY and UW288 cells for $4 \mathrm{~h}$ using different concentrations of bazedoxifene $(5,10$ and $20 \mu \mathrm{M})$ and then added exogenous IL-6 $(10 \mathrm{ng} / \mathrm{ml})$ to stimulate cell proliferation for $20 \mathrm{~h}$. Cell proliferation was determined by using $\mathrm{BrdU}$ incorporation and the results are presented in Fig. 2B. Cell proliferation was inhibited in a dose-responsive manner with the largest recorded for $20 \mu \mathrm{M}$. We also compared the inhibitory effects of bazedoxifene with those of the GP130 inhibitor, SC144 and the STAT3 inhibitor, BP-1-102 on IL-6 induced cell proliferation of DAOY and UW288 cells (Fig. 2B), and found that these agents inhibit IL-6-induced medulloblastoma cell proliferation.

Bazedoxifene reverses IL-6-induced STAT3 phosphorylation in medulloblastoma cells. STAT3 phosphorylation can be upregulated by exogenous IL-6, therefore, we sought to determine the effect of bazedoxifene on the expression of IL-6 stimulated STAT3 phosphorylation. We pretreated

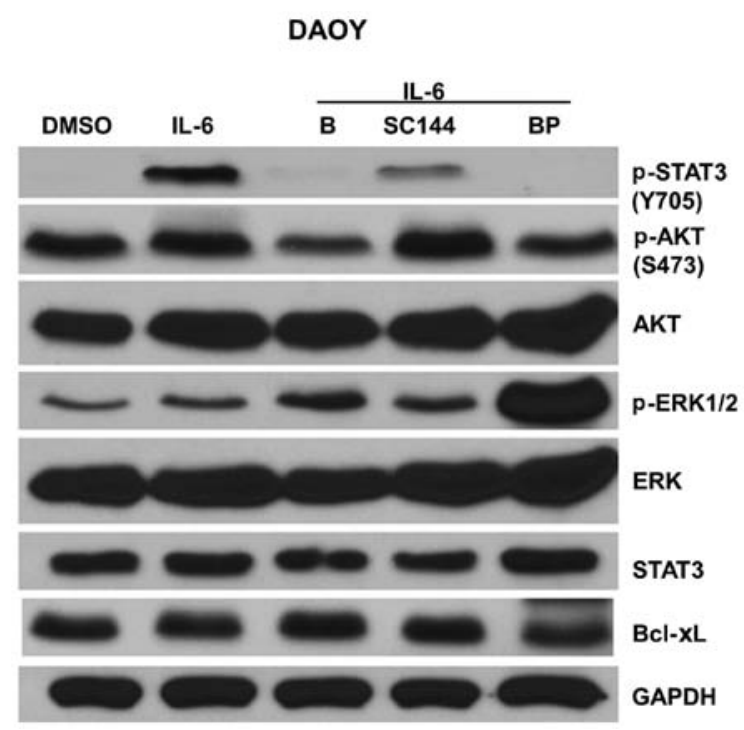

Figure 3. Bazedoxifene and other inhibitors downregulated IL-6 induced STAT3 phosphorylation in medulloblastoma cells. DAOY cells were pretreated with bazedoxifene $(20 \mu \mathrm{M}), \mathrm{SC} 144(20 \mu \mathrm{M})$, or BP-1-102 $(10 \mu \mathrm{M})$ for $4 \mathrm{~h}$, and then treated with recombinant human IL-6 $(10 \mathrm{ng} / \mathrm{ml})$ for $30 \mathrm{~min}$ to induce p-STAT3. B, bazedoxifene; BP, BP-1-102.

DAOY cells with bazedoxifene $(20 \mu \mathrm{M})$ for $4 \mathrm{~h}$ followed by stimulation with IL-6 $(10 \mathrm{ng} / \mathrm{ml})$ for $30 \mathrm{~min}$. As shown in Fig. 3, we observed that IL-6-mediated stimulation of STAT3 phosphorylation was blocked by bazedoxifene in DAOY cells. 
A

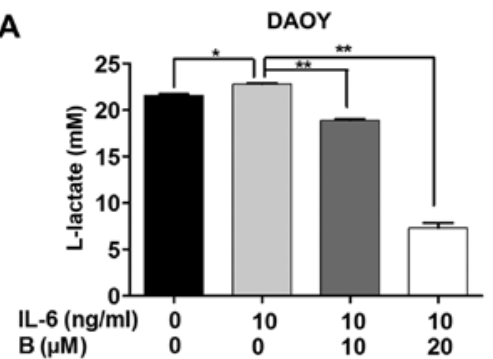

B

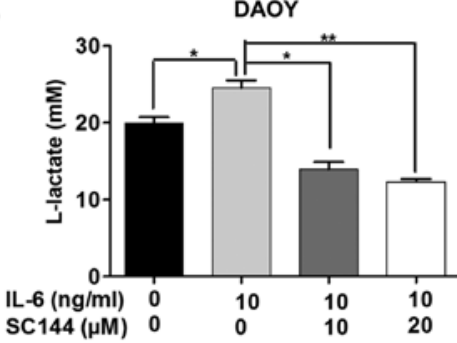

C

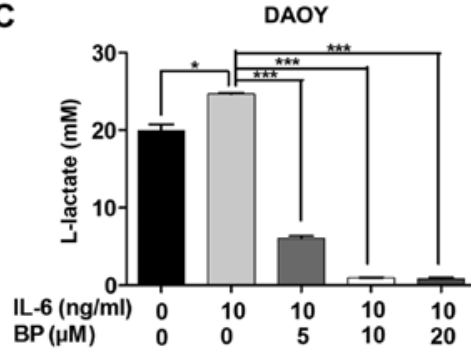

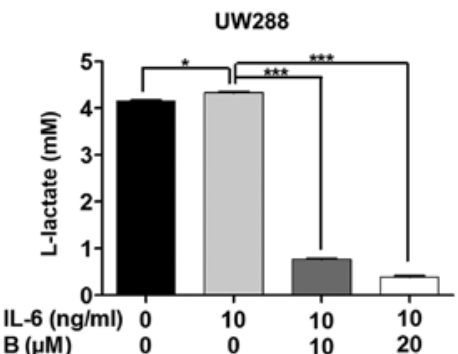
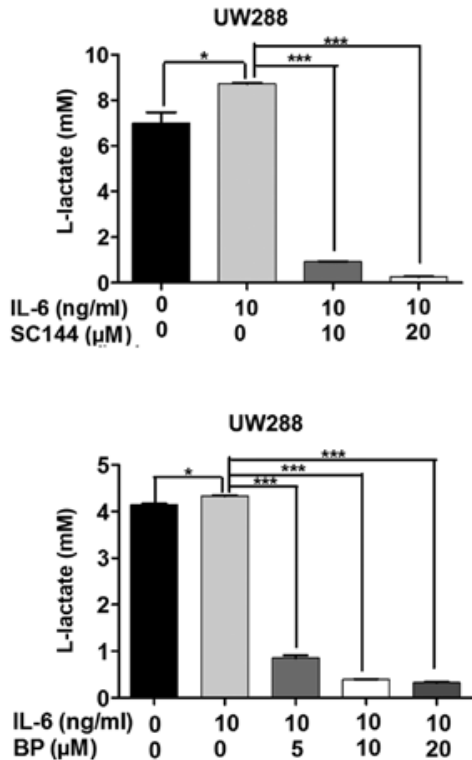

Figure 4. IL-6 promotes glycolysis in medulloblastoma cells and was blocked by bazedoxifene and other inhibitors. (A) Bazedoxifene, (B) SC144, and (C) BP-1-102. DAOY and UW288 cells were pretreated with inhibitors, bazedoxifene (5, 10 and $20 \mu \mathrm{M})$, SC144 (5, 10 and $20 \mu \mathrm{M})$, or BP-1-102 (5, 10 and $20 \mu \mathrm{M})$ for $4 \mathrm{~h}$, followed by addition of recombinant human IL-6 $(10 \mathrm{ng} / \mathrm{ml})$. After 48 -h treatment, the production of lactate was measured using glycolysis assay. B, bazedoxifene; BP, BP-1-102. ${ }^{*} \mathrm{P}<0.05,{ }^{* *} \mathrm{P}<0.01,{ }^{* * * *} \mathrm{P}<0.001$.

These results lend support to bazedoxifene functioning as a potent inhibitor of IL6/GP130/STAT3 phosphorylation in medulloblastoma cells.

Bazedoxifene attenuates IL-6-stimulated glycolysis in medulloblastoma cells. The enhanced flux of glucose to lactate by tumors as compared with normal tissues as previously observed by Warburg and coworkers $(38,39)$. To investigate the effect of IL-6 signaling on glucose metabolism in medulloblastoma cells, we first treated DAOY and UW288 cell lines with recombinant human IL-6 and observed the changes in lactate production. As a result, human IL-6 was shown to promote the uptake of glucose and increased its metabolite, lactate (Fig. 4). Notably, bazedoxifene treatment resulted in a dose-dependent decrease in lactate, indicating that bazedoxifene treatment decreases tumor cell glycolysis, which is mediated through the IL-6 signaling pathway in medulloblastoma cells. We tested whether the GP130 inhibitor, SC144 and the STAT3 inhibitor, BP-1-102 could block glucose metabolism induced by IL-6. As expected, SC144 and BP-1-102 effectively attenuated lactate production in DAOY and UW288 medulloblastoma cells.

Bazedoxifene treatment results in reduced colony formation. To further test the therapeutic potential of bazedoxifene against medulloblastoma cells, a colony forming assay was performed in medulloblastoma cells. We treated DAOY and UW288 cells with bazedoxifene and SC144 for $16 \mathrm{~h}$, followed by re-seeding the same number of viable cells at very low cell densities. After incubation for 2 weeks, cells were then fixed and stained. We found that bazedoxifene effectively reduced the dose-dependent colony forming capacity in DAOY and UW288 cells more potently than SC144 (Fig. 5).

\section{Discussion}

Medulloblastoma is an aggressive brain tumor with a high recurrence rate. The primary therapy of medulloblastoma includes maximal tumor resection followed by craniospinal radiotherapy as well as chemotherapy $(40,41)$. Cisplatin and vincristine are two major drugs utilized in the treatment of medulloblastoma (42-44). However, resistance and therapyassociated side-effects limit the therapeutic effectiveness of these agents, which has spawned an intense search for novel, biologically-based therapeutic targets (45). IL-6 is a pleiotropic cytokine that is highly expressed in numerous types of cancer (19-21). Notably, mounting evidence suggests that IL-6 is overexpressed in another brain tumor, glioblastoma multiforme (GBM), where it plays a crucial role in enhancing proliferation, invasion and angiogenesis in vitro $(46,47)$, so IL-6 has been identified as a promising molecular target 


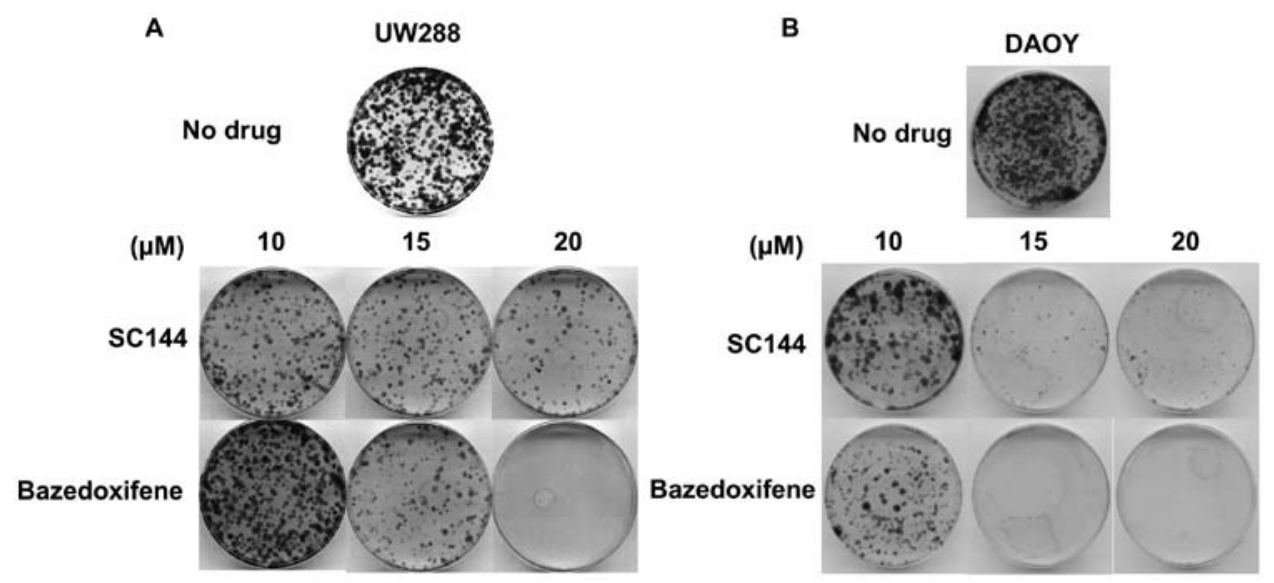

Figure 5. Bazedoxifene and SC144 inhibit the colony forming in medulloblastoma cells. (A) DAOY, and (B) UW288. Cells were treated with bazedoxifene $(10,15$ and $20 \mu \mathrm{M})$ and SC144 $(10,15$ and $20 \mu \mathrm{M})$ for $16 \mathrm{~h}$. After treatment, cells were harvested and reseeded on 6-cm plates with a drug-free medium for an additional incubation of 2 weeks. Colonies were fixed with methanol, and stained with crystal violet dye $(0.1 \% \mathrm{w} / \mathrm{v})$.

for glioblastoma therapy. Several novel IL-6 inhibitors have been recently developed (48). In our previous study, we found that DAOY and UW288 cells secreted high IL-6 levels (49). However, the importance of IL- 6 in the progression of medulloblastoma is poorly established. Herein, we demonstrated that IL-6 significantly stimulated cell viability and cell proliferation of DAOY and UW288 cells. Thus, our data combined with previous studies, support that targeting IL-6 signaling with small-molecule inhibitors is both a viable strategy in medulloblastoma treatment and one that deserves further study.

IL-6 signaling is mediated via its binding to the common signal transducer, GP130, which is part of hexameric IL-6/ IL-6R/GP130 complex that ultimately leads to the activation of JAK. JAK phosphorylates GP130, resulting in the recruitment and activation of STAT3 as well as other downstream factors (SHP2, Ras-MAPK and PI3K) (50). Herein, we observed that IL-6 upregulated the expression of phosphorylated STAT3, but had no significant effect on the phosphorylation of other protein kinase pathways, revealing that IL-6 mediated JAK/ STAT3 pathway is specifically upregulated by IL-6 in medulloblastoma cells. Therefore, we hypothesized that targeting of the IL-6/JAK/STAT3 axis could be an effective therapeutic approach for medulloblastoma.

Bazedoxifene is a third-generation SERM with improved selectivity and safety over tamoxifen that is currently approved by the FDA for use in the prevention of postmenopausal osteoporosis $(51,52)$. Madindoline A (MDL-A) inhibits the formation of the hexameric IL-6/IL-6R/GP130 signaling complex, since bazedoxifene is similar structure it led us to re-purpose bazedoxifene and test its anticancer activity in medulloblastoma and it could block IL-6 signaling in this cancer type (35). Additionally, phase III clinical studies demonstrated that bazedoxifene exhibited a favorable reproductive safety profile in postmenopausal women over periods of 3 and 7 years $(53,54)$, which suggests that bazedoxifene is an excellent drug candidate as an IL-6/GP130/STAT3 signaling antagonist. Thus, we investigated the in vitro effects of bazedoxifene in the inhibition of the IL-6/GP130/STAT3 axis in medulloblastoma cells. We showed that blocking the IL-6/GP130/STAT3 axis by bazedoxifene resulted in a significant reduction in medulloblastoma cell viability and proliferation. Notably, another previously reported GP130 inhibitor, SC144, and the STAT3 inhibitor, BP-1-102, also effectively reduced medulloblastoma cell viability and proliferation mediated by IL-6. Furthermore, bazedoxifene inhibited IL-6-mediated STAT3 phosphorylation in DAOY cells, as did the IL-6 signaling pathway inhibitors, SC144 and BP-1-102. Our findings further support our hypothesis that the inhibition of IL-6/GP130/STAT3 signaling pathway is a viable strategy for medulloblastoma therapy.

Enhanced aerobic glycolysis is one of the prominent features of most types of cancer cells, and it is important in the facilitation of cancer cell proliferation energy provision $(48,55)$. Although a recent study has showed that IL-6-mediated promotion of glucose metabolism is dependent on the JAK/STAT3 signaling pathway through the increased expression of hexokinase 2 and 6-phosphofructo-2-kinase/ fructose-2,6-bisphosphatase-3 (PFKRB-3) $(56,57)$, it is unclear whether IL-6 can enhance glycolysis via the IL-6/ GP130/STAT3 axis to provide biomass intermediates and energy in medulloblastoma progression. In view of this, targeting the IL-6/GP130/STAT3 pathway to inhibit glycolysis might be a therapeutic approach for medulloblastoma. The present study demonstrated the critical role of IL-6 in medulloblastoma progression and its part in promoting glycolysis. Specifically, downregulation of IL-6/GP130/STAT3 signaling by bazedoxifene treatment reduced IL-6-mediated glycolysis in medulloblastoma cells. Furthermore, the GP130 inhibitor, SC144 and the STAT3 inhibitor, BP-1-102 also decreased IL-6-stimulated glycolysis in medulloblastoma cells, which suggests that this signaling pathway could be a potential target in medulloblastoma treatment. Strikingly, our data demonstrated that the antitumor effects of bazedoxifene through inhibition of colony formation of medulloblastoma cells were more potent than the inhibition by SC144. Additionally, bazedoxifene has been documented with neuroprotective potential, suggesting that it can permeate the blood-brain barrier which is essential for the treatment of brain tumors $(58,59)$.

In conclusion, this study demonstrated that IL-6 plays a critical role in medulloblastoma cell viability, cell proliferation and glycolysis and it promotes medulloblastoma progression, implicating IL-6 signaling as a potential molecular target for medulloblastoma treatment. Furthermore, we found that 
downregulation of the IL-6/GP130/STAT3 pathway using bazedoxifene impairs medulloblastoma cell viability and proliferation, reduces glycolysis and disrupts clonogenicity. Our findings provide preclinical in vitro evidence for a potential therapeutic role of bazedoxifene for medulloblastoma. Additional studies are required to determine optimal strategies for incorporating this agent for use in children with medulloblastoma. In particular, future investigation would be needed in order to evaluate the use of bazedoxifene in combination with other agents.

\section{Acknowledgements}

This study was supported by the NIH/NINDS 1R01NS 087213-01A1 grant and the University of Maryland School of Medicine and Comprehensive Cancer Center start up fund.

\section{References}

1. Ostrom QT, Gittleman H, Fulop J, Liu M, Blanda R, Kromer C, Wolinsky Y, Kruchko C and Barnholtz-Sloan JS: CBTRUS statistical report: Primary brain and central nervous system tumors diagnosed in the United States in 2008-2012. Neuro-oncol 17 (Suppl 4): ivl-iv62, 2015.

2. Louis DN, Perry A, Reifenberger G, von Deimling A, FigarellaBranger D, Cavenee WK, Ohgaki H, Wiestler OD, Kleihues P and Ellison DW: The 2016 World Health Organization classification of tumors of the central nervous system: A summary. Acta Neuropathol 131: 803-820, 2016.

3. Taylor MD, Northcott PA, Korshunov A, Remke M, Cho Y-J, Clifford SC, Eberhart CG, Parsons DW, Rutkowski S, Gajjar A, et al: Molecular subgroups of medulloblastoma: The current consensus. Acta Neuropathol 123: 465-472, 2012.

4. Robinson G, Parker M, Kranenburg TA, Lu C, Chen X, Ding L, Phoenix TN, Hedlund E, Wei L, Zhu X, et al: Novel mutations target distinct subgroups of medulloblastoma. Nature 488: 43-48, 2012.

5. Gajjar A, Chintagumpala M, Ashley D, Kellie S, Kun LE, Merchant TE, Woo S, Wheeler G, Ahern V, Krasin MJ, et al Risk-adapted craniospinal radiotherapy followed by high-dose chemotherapy and stem-cell rescue in children with newly diagnosed medulloblastoma (St Jude Medulloblastoma-96) Long-term results from a prospective, multicentre trial. Lancet Oncol 7: 813-820, 2006

6. Northcott PA, Jones DT, Kool M, Robinson GW, Gilbertson RJ, Cho Y-J, Pomeroy SL, Korshunov A, Lichter P, Taylor MD, et al: Medulloblastomics: The end of the beginning. Nat Rev Cancer 12: 818-834, 2012

7. von Hoff K, Hinkes B, Gerber NU, Deinlein F, Mittler U, Urban C, Benesch M, Warmuth-Metz M, Soerensen N, Zwiener I, et al: Long-term outcome and clinical prognostic factors in children with medulloblastoma treated in the prospective randomised multicentre trial HIT'91. Eur J Cancer 45: 1209-1217, 2009.

8. Hunter CA and Jones SA: IL- 6 as a keystone cytokine in health and disease. Nat Immunol 16: 448-457, 2015.

9. Grivennikov SI and Karin M: Inflammatory cytokines in cancer: Tumour necrosis factor and interleukin 6 take the stage. Ann Rheum Dis 70 (Suppl 1): i104-i108, 2011.

10. Chang CH, Hsiao CF, Yeh YM, Chang GC, Tsai YH, Chen YM, Huang MS, Chen HL, Li YJ, Yang PC, et al: Circulating interleukin-6 level is a prognostic marker for survival in advanced nonsmall cell lung cancer patients treated with chemotherapy. Int J Cancer 132: 1977-1985, 2013.

11. Grivennikov S, Karin E, Terzic J, Mucida D, Yu G-Y, Vallabhapurapu S, Scheller J, Rose-John S, Cheroutre H, Eckmann L, et al: IL-6 and Stat3 are required for survival of intestinal epithelial cells and development of colitis-associated cancer. Cancer Cell 15: 103-113, 2009.

12. Yeoh GC, Ernst M, Rose-John S, Akhurst B, Payne C, Long S, Alexander W, Croker B, Grail D and Matthews VB: Opposing roles of gp130-mediated STAT-3 and ERK-1/2 signaling in liver progenitor cell migration and proliferation. Hepatology 45: 486-494, 2007.
13. Wegiel B, Bjartell A, Culig $\mathrm{Z}$ and Persson JL: Interleukin-6 activates PI3K/Akt pathway and regulates cyclin A1 to promote prostate cancer cell survival. Int J Cancer 122: 1521-1529, 2008.

14. Wei L-H, Kuo M-L, Chen C-A, Chou C-H, Lai K-B, Lee C-N and Hsieh C-Y: Interleukin- 6 promotes cervical tumor growth by VEGF-dependent angiogenesis via a STAT3 pathway. Oncogene 22: 1517-1527, 2003.

15. Oh K, Lee O-Y, Shon SY, Nam O, Ryu PM, Seo MW and Lee D-S: A mutual activation loop between breast cancer cells and myeloid-derived suppressor cells facilitates spontaneous metastasis through IL-6 trans-signaling in a murine model. Breast Cancer Res 15: R79, 2013.

16. Zou M, Zhang X and Xu C: IL6-induced metastasis modulators p-STAT3, MMP-2 and MMP-9 are targets of 3,3'-diindolylmethane in ovarian cancer cells. Cell Oncol (Dordr) 39: 47-57, 2016.

17. Mauer J, Denson JL and Brüning JC: Versatile functions for IL-6 in metabolism and cancer. Trends Immunol 36: 92-101, 2015.

18. Taga T and Kishimoto T: Gp130 and the interleukin- 6 family of cytokines. Annu Rev Immunol 15: 797-819, 1997.

19. Miura T, Mitsunaga S, Ikeda M, Shimizu S, Ohno I, Takahashi H, Furuse J, Inagaki M, Higashi S, Kato H, et al: Characterization of patients with advanced pancreatic cancer and high serum interleukin-6 levels. Pancreas 44: 756-763, 2015.

20. Nakashima J, Tachibana M, Horiguchi Y, Oya M, Ohigashi T, Asakura $\mathrm{H}$ and Murai M: Serum interleukin 6 as a prognostic factor in patients with prostate cancer. Clin Cancer Res 6: 2702-2706, 2000.

21. Dethlefsen C, Højfeldt G and Hojman P: The role of intratumoral and systemic IL-6 in breast cancer. Breast Cancer Res Treat 138: 657-664, 2013.

22. Hibi M, Murakami M, Saito M, Hirano T, Taga $T$ and Kishimoto T: Molecular cloning and expression of an IL-6 signal transducer, gp130. Cell 63: 1149-1157, 1990.

23. Mihara M, Hashizume M, Yoshida H, Suzuki M and Shiina M: IL-6/IL-6 receptor system and its role in physiological and pathological conditions. Clin Sci (Lond) 122: 143-159, 2012.

24. Leu C-M, Wong F-H, Chang C, Huang S-F and Hu CP: Interleukin-6 acts as an antiapoptotic factor in human esophageal carcinoma cells through the activation of both STAT3 and mitogen-activated protein kinase pathways. Oncogene 22: 7809-7818, 2003

25. Jones SA, Scheller J and Rose-John S: Therapeutic strategies for the clinical blockade of IL-6/gp130 signaling. J Clin Invest 121: 3375-3383, 2011.

26. Garbers C, Aparicio-Siegmund S and Rose-John S: The IL-6/ gp130/STAT3 signaling axis: Recent advances towards specific inhibition. Curr Opin Immunol 34: 75-82, 2015.

27. Roxburgh CS and McMillan DC: Therapeutics targeting innate immune/inflammatory responses through the interleukin-6/JAK/ STAT signal transduction pathway in patients with cancer. Transl Res 167: 61-66, 2016.

28. Yao X, Huang J, Zhong H, Shen N, Faggioni R, Fung M and Yao Y: Targeting interleukin-6 in inflammatory autoimmune diseases and cancers. Pharmacol Ther 141: 125-139, 2014.

29. Xu S and Neamati N: gp130: a promising drug target for cancer therapy. Expert Opin Ther Targets 17: 1303-1328, 2013.

30. Bournazou E and Bromberg J: Targeting the tumor microenvironment: JAK-STAT3 signaling. JAK-STAT 2: e23828, 2013.

31. Heo T-H, Wahler J and Suh N: Potential therapeutic implications of IL-6/IL-6R/gp130-targeting agents in breast cancer. Oncotarget 7: 15460-15473, 2016.

32. Wang S-W and Sun Y-M: The IL-6/JAK/STAT3 pathway: Potential therapeutic strategies in treating colorectal cancer (Review). Int J Oncol 44: 1032-1040, 2014.

33. Calabrese LH and Rose-John S: IL-6 biology: Implications for clinical targeting in rheumatic disease. Nat Rev Rheumatol 10: 720-727, 2014.

34. Tanaka T, Narazaki M and Kishimoto T: Therapeutic targeting of the interleukin-6 receptor. Annu Rev Pharmacol Toxicol 52: 199-219, 2012.

35. Li H, Xiao H, Lin L, Jou D, Kumari V, Lin J and Li C: Drug design targeting protein-protein interactions (PPIs) using multiple ligand simultaneous docking (MLSD) and drug repositioning: Discovery of raloxifene and bazedoxifene as novel inhibitors of IL-6/GP130 interface. J Med Chem 57: 632-641, 2014.

36. Wu X, Cao Y, Xiao H, Li C and Lin J: Bazedoxifene as a novel GP130 inhibitor for pancreatic cancer therapy. Mol Cancer Ther 15: 2609-2619, 2016.

37. Franken NA, Rodermond HM, Stap J, Haveman J and van Bree C: Clonogenic assay of cells in vitro. Nat Protoc 1: 2315-2319, 2006. 
38. Racker E: Bioenergetics and the problem of tumor growth. Am Sci 60: 56-63, 1972 .

39. Koppenol WH, Bounds PL and Dang CV: Otto Warburg's contributions to current concepts of cancer metabolism. Nat Rev Cancer 11: 325-337, 2011.

40. Jozwiak J, Grajkowska W and Wlodarski P: Pathogenesis of medulloblastoma and current treatment outlook. Med Res Rev 27: 869-890, 2007.

41. Massimino M, Cefalo G, Riva D, Biassoni V, Spreafico F, Pecori E, Poggi G, Collini P, Pollo B, Valentini L, et al: Long-term results of combined preradiation chemotherapy and age-tailored radiotherapy doses for childhood medulloblastoma. J Neurooncol 108: 163-171, 2012.

42. Packer RJ, Sutton LN, Elterman R, Lange B, Goldwein J, Nicholson HS, Mulne L, Boyett J, D'Angio G, WechslerJentzsch K, et al: Outcome for children with medulloblastoma treated with radiation and cisplatin, $\mathrm{CCNU}$, and vincristine chemotherapy. J Neurosurg 81: 690-698, 1994.

43. Rutkauskiene $\mathrm{G}$ and Labanauskas L: Treatment of patients of high-risk group of medulloblastoma with the adjuvant lomustine, cisplatin, and vincristine chemotherapy. Medicina (Kaunas) 41: 1026-1034, 2005.

44. Rood BR, MacDonald TJ and Packer RJ: Current treatment of medulloblastoma: Recent advances and future challenges. Semin Oncol 31: 666-675, 2004

45. Samkari A, White JC and Packer RJ: Medulloblastoma: Toward biologically based management. Semin Pediatr Neurol 22: 6-13, 2015.

46. Zanotto-Filho A, Gonçalves RM, Klafke K, de Souza PO, Dillenburg FC, Carro L, Gelain DP and Moreira JCF: Inflammatory landscape of human brain tumors reveals an $\mathrm{NF \kappa B}$ dependent cytokine pathway associated with mesenchymal glioblastoma. Cancer Lett 390: 176-187, 2017

47. Liu Q, Li G, Li R, Shen J, He Q, Deng L, Zhang C and Zhang J: IL-6 promotion of glioblastoma cell invasion and angiogenesis in U251 and T98G cell lines. J Neurooncol 100: 165-176, 2010.

48. Kumari N, Dwarakanath BS, Das A and Bhatt AN: Role of interleukin-6 in cancer progression and therapeutic resistance. Tumour Biol 37: 11553-11572, 2016.

49. Ball S, Li C, Li P-K and Lin J: The small molecule, LLL12, inhibits STAT3 phosphorylation and induces apoptosis in medulloblastoma and glioblastoma cells. PLoS One 6: e18820, 2011.

50. Heinrich PC, Behrmann I, Haan S, Hermanns HM, Müller-Newen $G$ and Schaper F: Principles of interleukin (IL)-6-type cytokine signalling and its regulation. Biochem J 374: 1-20, 2003.
51. Chines AA and Komm BS: Bazedoxifene acetate: A novel selective estrogen receptor modulator for the prevention and treatment of postmenopausal osteoporosis. Drugs Today 45: 507-520, 2009.

52. Komm BS, Kharode YP, Bodine PV, Harris HA, Miller CP and Lyttle CR: Bazedoxifene acetate: A selective estrogen receptor modulator with improved selectivity. Endocrinology 146: 3999-4008, 2005.

53. Archer DF, Pinkerton JV, Utian WH, Menegoci JC, de Villiers TJ, Yuen CK, Levine AB, Chines AA and Constantine GD: Bazedoxifene, a selective estrogen receptor modulator: Effects on the endometrium, ovaries, and breast from a randomized controlled trial in osteoporotic postmenopausal women. Menopause 16: 1109-1115, 2009.

54. Palacios S, de Villiers TJ, Nardone FC, Levine AB, Williams R, Hines T, Mirkin S, Chines AA and Group BS; BZA Study Group: Assessment of the safety of long-term bazedoxifene treatment on the reproductive tract in postmenopausal women with osteoporosis: Results of a 7-year, randomized, placebo-controlled, phase 3 study. Maturitas 76: 81-87, 2013.

55. Vander Heiden MG, Cantley LC and Thompson CB: Understanding the Warburg effect: The metabolic requirements of cell proliferation. Science 324: 1029-1033, 2009.

56. Ando M, Uehara I, Kogure K, Asano Y, Nakajima W, Abe Y, Kawauchi $\mathrm{K}$ and Tanaka N: Interleukin 6 enhances glycolysis through expression of the glycolytic enzymes hexokinase 2 and 6-phosphofructo-2-kinase/fructose-2,6-bisphosphatase-3. J Nippon Med Sch 77: 97-105, 2010.

57. Han J, Meng Q, Xi Q, Zhang Y, Zhuang Q, Han Y, Jiang Y, Ding $Q$ and Wu G: Interleukin-6 stimulates aerobic glycolysis by regulating PFKFB3 at early stage of colorectal cancer. Int J Oncol 48: 215-224, 2016.

58. Ciriza I,CarreroP, Azcoitia I,Lundeen SG and Garcia-Segura LM: Selective estrogen receptor modulators protect hippocampal neurons from kainic acid excitotoxicity: Differences with the effect of estradiol. J Neurobiol 61: 209-221, 2004.

59. Castelló-Ruiz M, Torregrosa G, Burguete MC, Miranda FJ, Centeno JM, López-Morales MA, Gasull T and Alborch E: The selective estrogen receptor modulator, bazedoxifene, reduces ischemic brain damage in male rat. Neurosci Lett 575: 53-57, 2014. 